\title{
Heces caninas: un riesgo permanente y sin control para la salud pública
}

\author{
Canine feces: a permanent and uncontrolled risk to public health \\ Iván Renato Zúñiga Carrasco,* Janett Caro Lozano* \\ * Jefe del Departamento de Epidemiología. UMF Núm. 223, IMSS, Lerma, México. \\ ‡ Jefa del Departamento de Epidemiología. HGZ C/MF Núm. 1, IMSS, Chetumal, Quintana Roo.
}

RESUMEN

En México y en el mundo se han reportado 19 géneros de parásitos entéricos y uno respiratorio presentes en las heces caninas. En la Ciudad de México se ha calculado la presencia de alrededor de medio millón de perros y el 30\% llega a defecar en cualquier lugar. Este excremento se desintegra y se convierte en partículas, las cuales flotan en el aire junto con otros contaminantes. Se estima que de cinco a 50 toneladas diarias flotan en el aire. Hay microorganismos que se pueden transmitir de perro a hombre como son: parasitosis, ciertas neumonías y problemas alérgicos en personas sensibles al excremento. Aunque una persona no tenga mascotas, puede tener contacto con las excretas de la mascota de su vecino o por lo menos con las heces de algún canino de las cercanías.

Palabras clave: Perro, heces, contaminación ambiental, parásitos.

\section{INTRODUCCIÓN}

En México y en el mundo se han reportado 19 géneros de parásitos entéricos y uno respiratorio presentes en las heces caninas, de los cuales $73 \%$ tienen potencial zoonótico. ${ }^{1}$

En la Ciudad de México se ha calculado la presencia alrededor de medio millón de perros y el 30\% llega a defecar en cualquier lugar. Este excremento se desintegra y se convierte en partículas, las cuales flotan en el aire junto con otros contaminantes. Se estima que de cinco a 50 toneladas diarias flotan en el aire. Estos datos, aunque parecen exagerados, no

Financiamiento: Ninguno.

Conflicto de intereses: Ninguno.

https://dx.doi.org/10.35366/94417

Rev Latin Infect Pediatr 2020; 33 (2): 74-77

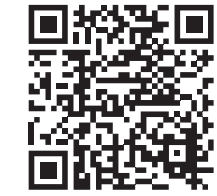

\section{ABSTRACT}

In Mexico and in the world, 19 genera of enteric parasites and one respiratory have been reported in canine feces. In Mexico City the presence has been estimated around half a million dogs and $30 \%$ get to defecate anywhere. This excrement disintegrates into particles which float in the air along with other contaminants. It is estimated that five to 50 tons per day float in the air. There are microorganisms that can be transmitted from dog to man such as: parasitosis, certain pneumonia and allergic problems in people sensitive to excrement. Even if a person does not have pets, they can have contact with the excreta of their neighbor's pet or at least with the feces of a nearby canine.

Keywords: Dog, feces, environmental pollution, parasites.

lo son, simplemente por la cantidad de deyecciones que no tienen ningún control ni manejo. Los caninos que habitan en azoteas y en la vía pública son los que más contaminan, ya que este material no se limpia, sino que se deshidrata, pulveriza y nebuliza en toneladas de excremento en el medio ambiente. ${ }^{2}$

Hay microorganismos que se pueden transmitir de perro a hombre como son: parasitosis, ciertas neumonías y problemas alérgicos en personas sensibles al excremento. ${ }^{2}$

\section{EVIDENCIAS}

El perro, Canis familiaris, desempeña un papel importante en la transmisión de infecciones helmínticas de tipo zoonóticas. Los caninos pueden transmitir diversas especies de helmintos zoonóticos, tales como Toxocara spp., Trichuris vulpis, Ancylostoma spp., Spirocerca spp., Uncinaria spp., Strongyloides 
Rev Latin Infect Pediatr 2020; 33 (2): 74-77

spp., entre otros; estos pueden ocasionar en los humanos diversas patologías de tipo cutánea, visceral, ocular y cerebral. Las excretas de los animales son un material biológico altamente contaminante de suelo, aire, agua y alimentos, los cuales constituyen las principales vías de transmisión. La contaminación ambiental por huevecillos y larvas de parásitos caninos constituye un severo riesgo de salud pública. ${ }^{3}$

El contacto con los caninos es frecuente, un número considerable de los hogares en Latinoamérica tienen perros, usualmente se alojan dentro de las casas y viven en contacto estrecho con sus dueños, incluso a veces comparten la cama con alguno de los habitantes de la casa. Aunque una persona no tenga mascotas, puede tener contacto con las excretas de la mascota de su vecino o por lo menos con las heces de algún canino de las cercanías. El perro doméstico es el principal agente involucrado en la contaminación de cualquier lugar público, y la población infantil es uno de los grupos más expuestos a los focos de transmisión, debido a su mayor tendencia a algunas actividades como el juego con las mascotas, el contacto con el suelo, el pasto y la tendencia a la geofagia. ${ }^{3}$

Los huevecillos de Toxocara spp. Ilegan al suelo por las heces de perros y gatos infectados. Éstos requieren varias semanas para embrionarse, pero se mantienen viables e infectantes durante varios meses. Los helmintos que afectan el intestino de los canes domésticos constituyen un alto riesgo, en especial cuando se tiene un deficiente manejo sanitario de los animales y prácticas inadecuadas en el manejo de sus excretas, particularmente cuando realizan sus deposiciones en zonas públicas. ${ }^{3}$

Los caninos, cuya función primordial es la de ser animales de compañía, cumplen un papel predominante en la transmisión de infecciones causadas por ciertos parásitos, entre los cuales se destacan: helmintos como uncinarias, Toxocara canis, Toxascaris leonina, Strongyloides spp., Dipylidium caninum, Trichuris vulpis; larva migrans: visceral, ocular, cutánea hidatidosis, Echinococcus granulosus, T. canis; y protozoos: Entamoeba spp., Blastocystis spp., Giardia spp., Chilomastix spp., Giardia duodenalis. ${ }^{3}$

En un estudio realizado por González y colegas, un muestreo de heces de perro evidenció que $87.5 \%$ presentan diferentes formas parasitarias, y éstos se distribuyen de la siguiente manera: para helmintos uncinarias $20.6 \%$, T. canis $8.6 \%$ y Strongyloides spp. con $2.9 \%$; en tanto que los protozoos Entamoeba spp. con 21.1\%; seguida por
Blastocystis spp. y Giardia spp. con 18.3 y $16 \%$, respectivamente. ${ }^{4}$

Los datos consignados permitieron identificar que $84.6 \%$ corresponde a perros, los cuales se denominaron con varios nombres: de la calle, de raza criolla o mestiza. El 15.4\% correspondió a razas puras, entre las cuales se destacaron: labrador, pit bull, french poodle, pinscher, entre otras. Los caninos se categorizaron en dos grupos etarios, el primero lo conformaron animales de cero a dos años y mayores a dos. Se halló asociación estadísticamente significativa entre la edad y la presencia de agentes parasitarios como Strongyloides spp. y D. caninum. ${ }^{4}$

En otro estudio realizado por Vélez y colaboradores se colectaron 180 muestras de heces en cinco meses y de las 10 zonas seleccionadas se registró fecalismo canino. La biodiversidad parasitaria mostrada no presentó un patrón homogéneo, los parásitos identificados fueron $T$. canis, Toxascaris leonina, D. caninum, A. caninum, Trichuris vulpis e Isospora spp.; los helmintos con mayor prevalencia fueron los nematodos $T$. canis, $A$. caninum y el cestodo $D$. caninum. En $73.3 \%$ de las muestras se registró la presencia de parásitos. De éstas presentaron una variación de una a tres especies de parásitos.

La infección por T. canis en el hombre se presenta por la ingestión de la larva, que está presente en suelos y otros fómites contaminados, incluido el pelaje del perro. El éxito que puede tener $A$. caninum para infectar al hombre radica en que las vías de contagio son la ingestión y la penetración transcutánea, esta última se presenta cuando la gente camina descalza en sitios contaminados o cuando el bañista pone su cuerpo en contacto con la arena. Los canes marcan su territorio con secreciones de los sacos anales que eyectan voluntariamente durante la defecación; éstas se intensifican y esparcen cuando los perros rascan la tierra. Estas señales olfativas estimulan a otros caninos a defecar en el mismo lugar. ${ }^{1}$

En el estudio realizado por Martínez y su equipo se detectaron diferentes formas parasitarias en las muestras colectadas. La frecuencia de huevos de T. canis y de $A$. caninum fue de 19 y $18.5 \%$, respectivamente, y la de ooquistes de Isospora canis fue de $2.5 \% .^{5}$

El potencial de T. canis es enorme desde el punto de vista epidemiológico, debido a que sólo una hembra es capaz de producir hasta 200 mil huevecillos al día. La Organización Panamericana de la Salud (OPS) ha estimado que un gramo de excremento de un perro cachorro puede contener hasta 15 
mil huevecillos de Toxocara, que al ser evacuados en la vía pública son diseminados por la acción del pisoteo, viento, lluvia o vectores. Sus cubiertas, las cuales son muy gruesas, los hacen resistentes a los cambios ambientales y pueden sobrevivir por varios años. La superficie del suelo puede estar, en apariencia, «limpia» de cualquier rastro de heces; no obstante, la materia fecal se desintegra aunque no exista olor alguno y cualquier superficie puede estar infestada de parásitos. El suelo contaminado con huevecillos larvados de $T$. canis es la principal fuente de infección humana. ${ }^{5}$

Los parques de las ciudades son un riesgo constante para las poblaciones, ya que son los sitios idóneos para que los caninos defequen por todos lados, el suelo ofrecerá las condiciones necesarias para que los huevecillos sobrevivan durante meses e incluso años. Es importante recalcar lo comentado anteriormente, ya que la población infantil es la más vulnerable, sobre todo los menores de ocho años de edad, quienes están más en contacto con la tierra contaminada, y algunos de ellos y sus padres pueden llegar a tener hábitos higiénicos precarios. El riesgo de habitar en suelos contaminados con huevecillos de $T$. canis es tan grave que se han documentado casos de toxocariasis ocular congénita en recién nacidos, esto es debido a la pérdida de la visión, la cual sucede por efecto de la inflamación aguda de la retina y el nervio óptico. ${ }^{5}$

\section{MITOS SOBRE LAS HECES CANINAS}

La destacada salubrista Grace Robiou nos da una excelente descripción sobre los mitos que guarda el excremento canino:

\section{El excremento de perro es abono natural}

Popularmente se dice que las heces de perro contribuyen de buena forma al medioambiente porque es materia orgánica y biodegradable. Esta declaración es una tremenda falacia, ya que se intenta comparar con el estiércol de las vacas, el cual se utiliza en ocasiones como abono de terrenos; pero, el excremento de una vaca y la de un perro no están constituidos de lo mismo. La clave está, principalmente, en la dieta del animal; por lo general, las heces que son apropiadas para uso como abono contienen materia verde que ha sido digerida, de manera que las heces de vaca (un animal herbívoro) pueden hacer un buen abono natural, pero las de perro (un animal carnívoro) no.
Existen métodos en que los excrementos de los perros pueden utilizarse como abono, pero esto requiere de tratamiento previo, es decir, se puede utilizar un biodegradador o un aparato de composta para mezclar el excremento con un preparado a base de materia orgánica y bacterias con gran resistencia a altas temperaturas, para así producir un abono saludable para el jardín; pero todo lo anterior es complejo y en cierta manera con un costo elevado. ${ }^{6}$

\section{El perro sólo defeca tres trozos pequeños de heces al día}

No es sólo un perro, hablando de manera singular, hay que pensar a nivel macro de ciudad. Para ilustrar la magnitud del problema consideremos que un gramo de heces de perro tiene cerca de 23 millones de bacterias que pueden provocar diversos problemas de salud de corta o larga duración. Se estima que un perro de tamaño mediano (un perro de aproximadamente $11.33 \mathrm{~kg}$ ) evacúa un promedio de 600 gramos de excremento al día, esto representa un total de $18.14 \mathrm{~kg}$ de excremento al mes. Estamos hablando que ese mismo perro mediano contribuye a generar 920 millones de bacterias al mes. Ahora, traspasemos nuestros cálculos a 100,000 perros de cierta ciudad. Comparando lo anterior, un camino de ocho cilindros que hace $24,140 \mathrm{~km}$ al año posiblemente contamina menos que un perro tamaño mediano. Recordemos que no sólo los perros contaminan con su materia fecal, también gatos, aves, roedores y los mismos humanos que defecan al ras del suelo. ${ }^{6}$

El excremento de perro desaparece en el ambiente, ya que se seca o se integra al suelo

Las heces de perro al aire libre se secan y se convierten en polvo muy fino que respiramos o ingerimos al consumir alimentos preparados en la calle. En las regiones tropicales lo más común es ver que las heces comienzan a degradarse en el suelo hasta que caen las primeras lluvias. Lo anterior representa un problema ambiental, porque esa agua si no llega al drenaje terminará contaminando todo manto acuífero; por lo tanto, la posibilidad de utilizar esa agua para consumo humano sin tratamiento previo; su potencial para estar en contacto directo puede estar marcado en zonas recreativas donde acuden vacacionista principalmente bañistas. Las lluvias fuertes hacen que los desagües pluviales se 
Rev Latin Infect Pediatr 2020; 33 (2): 74-77

sobrecarguen, tal situación provoca que en algunas ciudades se mezclen las aguas negras con las aguas de escurrimiento conteniendo niveles descomunales de materia fecal. ${ }^{6}$

\section{Lo único que puede dar la ingesta de materia fecal canina es diarrea}

De las enfermedades diarreicas provocadas por el contacto con heces caninas podemos destacar la giardiasis y la criptosporidiosis. En determinadas personas (sobre todo niños, mujeres embarazadas y personas inmunodeprimidas) algunas de estas enfermedades pueden causar agravamiento del padecimiento y en ocasiones llegar a la muerte.

Hasta el momento ha habido esfuerzos de concientización e iniciativas, tales como llevar bolsas para la recolección de las heces o áreas incluyentes en los parques destinados para perros; aun así, un gran número de personas no recogen los excrementos. ${ }^{6}$

\section{CONCLUSIÓN}

Se puede culpar a los perros como los causantes de la gran cantidad de heces en la vía pública y parque; sin embargo, los responsables directos son los dueños, quienes de manera irresponsable dejan el excremento de su mascota en vez de llevarlo en una bolsa hasta su disposición final. Asimismo, otra situación importante es la falta de estrategias de salud para poder controlar (sin dañar los derechos de los animales) la gran cantidad de caninos que deambulan sin control alguno en cualquier pequeña, mediana o gran ciudad.

\section{REFERENCIAS}

1. Vélez L, Reyes K, Rojas D, Calderón M, Cruz J et al. Riesgo potencial de parásitos zoonóticos presentes en heces caninas en Puerto Escondido, Oaxaca. Salud Pública de México. 2014; 56 (6): 625-630.

2. Carrillo L. Contaminación por heces de perros y gatos. Gaceta Universitaria. [Consultado el 10/07/19] (4 de junio de 2001). En: http://www.gaceta.udg.mx/Hemeroteca/ paginas/208/208-5.PDF.

3. Peña I, Vidal F, Del Toro A, Hernández A, Zapata M, Margarita M. Zoonosis parasitarias causadas por perros y gatos, aspecto a considerar en Salud Pública de Cuba REDVET. Revista Electrónica de Veterinaria. 2017; 18 (10): 1-11.

4. González C; Giraldo J. Prevalencia de parásitos intestinales zoonóticos en caninos (Canis lupus familiaris) del área urbana del municipio de Coyaima (Tolima). Revista Med. 2015; 23(2):24-34

5. Martínez I, Gutiérrez E, Alpízar E, Pimienta R. Contaminación parasitaria en heces de perros, recolectadas en calles de la ciudad de San Cristóbal de Las Casas, Chiapas, México. Vet. Méx. 2008; 39 (2) 173-180.

6. Robiou G. Cuatro mitos sobre la caca de perro. 80 grados ciencia. Publicado: 9 de mayo de 2014. [Consultado: 10/07/19]. En: http://www.80grados.net/cuatro-mitos-sobrela-caca-de-perro/.

\section{Correspondencia:}

Dr. Iván Renato Zúñiga Carrasco E-mail: ivan.zuniga@imss.gob.mx 